\title{
Conservative Political Transformation Projects of the Russian Government: The Main Discourses of Contemporaneity
}

\author{
Alexey Y. Mamychev \\ Evgeniya Y. Kiyashko \\ Alla A. Timofeeva \\ Vladivostok State University of Economics and Service \\ Email: eldirect@mail.ru, mamychev@yandex.ru
}

Doi:10.5901/mjss.2015.v6n3s2p373

\begin{abstract}
The paper analyzes two main dominant political projects of transformation of the political system and state-legal organization in the post-Soviet territory - conservative one and modernizational one which differ in internal ambiguous and contradictory. The authors argue that the process of political transformation should be examined as a wider category than the concept of "modernization", which is a type of transformation processes which are interpret as evolutionary, revolutionary or pendulum forms of political institutions, the system of authoritative relations. It is proved that modern conservative projects of transformation of political life of the community, aimed at the formation of adequate and organic to socio-cultural environment public institutions of government, forms of organizations that meet the interests and values of society. At the same time, it is shown that in the twenty-first century in the post-Soviet territory, and in particular in the development of Russia's political organization a stable conservative strategy is restored. The paper the general characteristics are identified and the fundamental differences between conservative and modernist political programs are pointed out. Depending on the style of conservative thinking and fundamental civilizational standards of political organization such conservative platforms operating in Russian politics as traditsionalistic, neo-eurasistic, modernistic, postmodernistic and others are selected and analyzed in the article.
\end{abstract}

Keywords: authority, conservatism, modernization, political system, legal system.

\section{Introduction}

Conservatism as a style of political consciousness is a specific thought-activity structures, reflecting the way of knowledge and assessment of the current political reality, as well as public-authoritative practice aimed at safeguarding of the traditional state experience, rationalization and representation of stable irrational (extralegal, ethno-political, sociocultural, etc. ) dominants of national culture, their care and reproduction.

In today's changing political and legal reality a conservative style of thinking (despite the different nuances, program regulations, ideological preferences, etc.) is focused on the stability and continuity, on organizations providing unity and integrity, solidarity and justice preserving. The latter act as typeforming features of conservative type of political thinking, typical for various conservative teachings, doctrines, ideological platforms. In its turn, the content of conservative thinking may vary depending on the specific historical conditions, problems and etc.

Conservative strategy focuses on ethno-political and legal-cultural conditionality of social interaction of citizens, on formation and development of political organization, legal ordering, etc. At the same time it is assumed that because of these reasons (socio-cultural codes) citizens from one generation to another draw their identity, a certain order of relations. In its turn, the intrusion of alien society parameters of the political order, not knowing the limits of socio-cultural, legal and political modernization will eventually deplete stocks of historical memory, which depend on the stability and reproduction of the social system. Therefore, legal institutions and political structures cannot and should not be independent of the cultures in which they operate and serve. Moreover, the latter, per contra, must be assessed and controlled in terms of objectives and standards of social and cultural environment in which they operate.

In respect to conservative style of political thought - no matter how large-scaled may be transformational processes that entail the creation of new public institutions, the establishment of the latest regulatory and structural configuration, conditioning the new principles of legitimation, they lead to the fact that "newly-made" institutional regimes 
either adapt traditional forms and methods of social and legal interaction, or fully assimilate the latter without changing fundamentally the nature and content of these processes, or a new institutional order at all distorted beyond recognition, when confronted with the traditional context.

In this article a theoretical and practical analysis of the development of conservative way of thinking in the postSoviet territory will be offered and its representation in certain political programs and movements of contemporary Russian politics will be examined.

\section{Literature Review}

Analysis of the phenomenon of conservatism as a way of thinking and a certain structures of mentality of political actors was first proposed, as it is known, by know Karl Mannheim (K. Mannheim, 1994). The influence of the conservative style of thinking to real politics and political strategies of the different actors is obvious and indisputable. This fact has been repeatedly emphasized in various research projects (S.N. Eisenstadt, 1973; J. Buchanan, G. Tullok, 1962; S. Armagan and Ferreira M. Portugal, 2005; and E.S. Clemens and J.M. Cook, 1999). Grouping of various political programs and real political action can be, according to Frohock, grouped into certain "clusters of ideas" which contain the similar semantic concepts, strategies, actions (F. Frohock, 1978). On this idea and methodological practices we will rely in order to identify the links and relationships between the various modern conservative scholars and programs, general configuration of the central meanings and practices of conservatism.

In general, we adhere to the position that was justified by L.A. Tikhomirov, according to which conservatism is aimed not at standstill, but in the development of human institutions (public and legal, spiritual, moral, social and economic) which does not deny the past, but, on the contrary, presupposes and is based on the traditional cultural historical experience (L.A. Tikhomirov, 1992).

In contrast to fundamentalism and traditionalism, which are focused on regressive political movement, i.e. restoration of the original universal (primordial) traditions, lost shapes and patterns of social interaction (R. Guenon, 2002), which implies a negative attitude to all sorts of change, innovation, transformation, conservatism, on the other hand, "does not require the preservation of tradition unchanged in spite of everything, it only seeks to introduce these changes in the scope of "natural evolution" of the tradition itself" (V. Nikitaev, 2005).

Theoretical-methodological and practical terms of consideration of modern conservatism and its dominant discourses and new institutionalism are developed in the works of such authors as: P.J. DiMaggio, J. March, D. Norton, G. Olsen, R. Taylor, J. Wallis, A. Tabor, P. Hull, F. Eymard-Duvernay and others in which political institutions are interpreted widely, on the one hand, as formal rules, regulations, models, procedures and standards; and on the other hand as symbolic systems, cognitive scripts, socio-cultural, spiritual and moral models, which organize and manage the mental activity of people (P.A. Hall and R. Taylor, 1996; J.-L. Quermonne, 1986; R. Hoppe, 2002; P. Landort and L. Goldring, 2010; and J.G. March and J.P. Olsen, 1984).

Within the framework of neo-institutionalism conservative style of political thinking activity suggests as a central, axial idea the formation of adequate and organic to culture public institutions of government, forms of organizations that meet the interests and values of society. Therefore, the phrase "conservative transformation" - is not a phenomenon of postmodern discourse, which combines incompatible, combine opposites, etc., but the actual program of conservative political thinking: «Categorical juxtaposition of tradition and modernization occurs if the concept of "modernization" is associated only with borrowing of foreign experience and "tradition" refers to all the old and obsolete in the socio-political and public life. In this case, instead of "conservatism" it is more appropriate to use the term "reaction"», conservatives do not try to resist change, they are trying to make them manageable. Therefore, the researcher continues, "Conservatives saw the solutions to the problems facing the country, not in a radical revolutionary upheaval, but in gradual evolutionary system reform based on national experience» (A.V. Repnikov, 2007).

In which connection, at the end of the twentieth century, according to many researchers in the post-Soviet territory and in particular in the development of Russia's political organization a stable conservative strategy is being restored.

Moreover, the Institute of Comprehensive Social Studies of RAS a nationwide sociological study was conducted, which showed that the conservative-oriented views, spiritual and moral principles of the understanding of publicauthoritative field, traditional values and systems of social expectations "gradually restore its influence on society ... Value-semantic core of the Russian mentality continues to show remarkable steadiness and diversity. Even in the conditions of systemic transformation of Russian society, almost all aspects and problems of the modern world democracy and market economy, freedom and social responsibility, the relationship between the individuals, society and the state - receive specific sound and color in Russia"(M.K. Gorshkov, 2005). 


\section{Methods and Materials}

The fundamental methodological position, which is realized in this article, is that the perception of a new socio-political or institutional-legal experience, gained by a nation of certain transition (transformation) periods is performed through the principles of succession-reproducible emotional and psychological readiness and cognitive clichés adapted and used in accordance with the established style of political thinking that are realized (in the everyday behavior and interaction of citizens) in accordance with the basic national forms, regimes and models.

The current political reality with these positions cannot be viewed only as a result of rational-volitional efforts, especially of one concrete generation. It is formed and develops together with the formation and development of society, has similar patterns, principles and specific features. One should consider every stage of the development of political culture, on the one hand, as a relatively independent, whole (in terms of socio-cultural) stage of development of society; and on the other hand - to ascertain the integrity of the national political evolution, supported by social and cultural core of the social system, despite of all the twists and turns in the historical destiny of the nation state and the law.

In theoretical-methodological and practical aspects, one should point out general (similar) characteristics, as well as the fundamental differences between the modern conservative and modernistic strategies of political transformation. Thus, general, of course, is the justification of the need for change, focus on optimization, improvement, search for improved forms of political organization, adequate and effective means and mechanisms of control, social problems solving, and so on. Differences are actually a lot more and they are more serious and fundamental than is now believed. Those differences, generally speaking, include the following:

- first, the opposition of conservative and modernistic platforms due to the difference in interpretation of the social bases of political order. The first comes from the fact that society is built on the basis of certain structural integrity, it is dominated by a specific integral social systems ensuring political unity, public integrity, social and cultural identity, etc. While the second platform (based on liberal-democratic paradigm of political thinking), on the contrary, individualized will of subjects, not total socio-cultural super-systems is considered to be a basis of political order (Ch. Muouffe, 2000). These forms of integrity and unity are considered as forms of "suppression of the individual", "totalitarian means" of enslavement of civic engagement and practices of civil institutions development, etc :;

- second, the contradictions between the two platforms and, therefore, the strategies of the political system development is due to the relation of tradition and innovation. Conservative platform is characterized by a rigid connection between public policies and historical patterns of development of the social system, the dominant tradition and innovation. For example, S. Eisenstadt argued that innovation and tradition are not opposed to each other, on the contorary, in the right combination results in a stable and organic development of society, the political system, etc. He argued that the nature of the changes in any society is not arbitrary, it is specified from within by a tradition; in every society there are "real and symbolic events of the past, the procedure and the images of which are the core of the collective identity, the definition of measures and the nature of its social and cultural changes. Tradition in such a society is not only a symbol of continuity, but also a definition of the limits of innovation and the main criterion for their legality, as well as the criterion of social activity" (S.N. Eisenstadt, 1973).

In its turn, the modernist vector of transformation of state-legal organization (wider than the entire social system) "is based on the concept that individuals precede society, they are carriers of "natural rights", they are rational and motivated by a desire for personal use; same authority and tradition, limiting such individuals, are the prejudice and remnant that must be overcome and discarded" (V. Nikitaev, 2005).

In addition, according to many researchers since the mid twentieth century, every conservative teaching or doctrine is neo-conservatism as of "pure form" of conservative legal and political doctrines date from the end of XVIII - the middle of the twentieth century. After a specified period conservatism is losing its identity as a "retrospection of the past" (V.M. Muzaev); subsequent teachings and doctrines that differ by conservatively-oriented style of political thinking, are a hybrid, mixed variants, which today are supposed to be designated as a "neo-conservative program" (A.N. Okara, 2010).

\section{Findings and discussion}

\subsection{Traditionalistic ideological platform of conservative transformation and organization of the government}

Summarizing the development of conservative thinking style in the post- Soviet territory and its representation in the specific political programs and movements on the example of contemporary Russian politics select the most dominant ideological platform.

Traditionalistic ideological platform of conservative transformation and organization of the government is based on 
the restoration of the traditional ideological paradigm of the national perception of the state, government, politics and law, public-authoritative forms of interaction between individuals, society and the state. As a rule, as the "idea basic" base (idea-principle) principles of authoritative relations characteristic of the monarchist organization of Moscow period are taken.

In general, the traditional conservative thinking is characterized with mainly regressive attitude towards social and political values and ideals of the state and legal development. Thus, the period of formation and development of the Moscow statehood is treated in this ideological platform as a epochal and a fateful choice of Russia, defining nationalcultural archetype of the organization of authoritative relations, successively reproduced from generation to generation; i.e. this authoritative-law archetype serves as a forming idea of state-legal organization at different stages of the evolution of the domestic legal and political organization (A.I. Ovchinnikov, A.Y. Mamychev, A.V. Manastyrny and Tyurin M.E., 2009).

Moreover, national-cultural archetype formed in this era also serves as type-forming element in the national political culture, which mediates both the choice of models for organization of public-authoritative relations and typologically similar trends of development in different concrete-historical conditions. Consideration of the Moscow Statehood as a key socio-political code, which influenced and still influences on the development of political consciousness, is one of the key positions of the traditional conservative way of thinking. The radical distinguishing feature of the traditional conservative ideological platform is that the entire political entity should be based on a set of objectively existing historical factors that are interpreted by the system of absolute ideals and ideas.

At that the government intends to serve this common idea that developed during the inner, spiritual life (I.A. llyin, 2003), and because of the following of this general idea it is on the real altitude, its existence and position in society is due to that service.

Within this ideological platform different directions, justifying the principles of organization and transformation (primarily gradual evolutionary development based on national values, traditions, customs and so on.) of modern authoritative relations in society "coexist". The concept of "enlightened conservatism" can serve as a vivid example of upholding of traditionalistic structures in the public sphere. This concept implies a prompt return to the restoration of a strong government that is responsible for the socio-political and spiritual and moral development of the nation, as well as for the formation of class organization and popular government based on it. The problems of organization of authoritative relations are associated with traditionalistic autocratic principles. Exactly in the activity of the autocratic authority and its privileged class one must, in the opinion of the author, seek a role model, because, according to Mikhalkov, all significant social projects and major reforms aimed at optimization of the national legal system and modernization of various spheres of people's livelihoods, are successfully carried out only when they are carried out by the decision and under the control of the supreme authority. And the success of the latter is connected, as history shows, with a symphony interaction between the state, public and church leaders of Russia (N.S. Mikhalkov, 2010).

\subsection{Updated Eurasian (neo-eurasian) ideological platform}

Updated Eurasian (neo-eurasian) ideological platform is based on the philosophical and ideological basis of the prerevolutionary political scientists, philosophies, geopolitics, etc. Today Neo-eurasism is based on patriotic, conservative and traditionalistic political ideology, which comes from the "conviction that Russian civilization has its own original way, which has no analogues either in the West or in the East. This identity is taken as the supreme value, which must be strengthened and protected"(A.G. Dugin, 2004).

This project of conservative forms an idea and principles of civilized approach to the state, the government, society, politics, law, etc., substantiating the typological uniqueness of Russian public-authoritative relations and functioning political institutions. At the same time as the leading principles of authoritative relations in the national legal space the Eurasians point out:

- $\quad$ first, the revival of the role and messianic significance of Russia in Eurasia;

- second, the approval of the spiritual and moral standards in civilization and culture, as opposed to utilitarian authoritative relations of Western-European culture, consumer and individualistic changes of the social system development;

- third, the political organization of society, which should be based on justice, honor, morality, in contrast to corruption, political stagnation and anomia, legal nihilism and idealism, the power of capital and the oligarchy;

- fourth, the revival of the sovereignty of nations and national uniqueness of cultures in face of globalization, political standardization and unification of legal, cultural etc. typification;

fifth, it is the institutional and normative fixation in the current legislation and political practice of the principle of 
a new formation of an elite, based on a selection of people on the basis of merit, spiritual, moral and professional qualities, the development of the deontologic foundations of law-enforcement, judicial and other political and legal activities;

sixth, the creation of a social society, development and implementation of socially-oriented policy, ensuring solidarity and mutual support, as well as the preservation of social and political institutions of a socialist society in various spheres of life (health, education, housing and communal services, pensions and so on.);

seventh, the development of the system of patriotic education and formation of spiritual and moral standards of the individual, because "the Eurasians believe that consistent patriots and fully-fledged citizens of our homeland must confess one of the traditional religions. Eurasian movement - is a movement of traditionalists, believers or (at least) those who are on the way to the tradition"(Dugin A.G., 2004, p. 248);

- eighth, to the place of the nation-state a new type of political organization that combines the association of large continental spaces (here obviously the development of N.Y. Danilevsky ideas on the Common Slavic super-allied state in Eurasia) with a complex, multi-dimensional system of national , cultural and economic autonomy should come.

\subsection{Modernist conservative ideological platform}

Modernist conservative ideological platform includes projects of conservative ideologies created by official authority, combining a set of modernizational (modern, contemporary) and stable socio-cultural values, ideas and concepts. In particular the official ideology of authority combines different set of values, such as freedom, equality, justice, appeal to the past as a source of future achievements, continuity and evolutionary development, the Orthodox faith, moral standards, family, property, state, justice, law and order, freedom in connection with its responsibility and protection of human dignity, patriotism and so on.

However, the use of the ideology of combination of conservative modern (modernization and innovation) ideas and values is, from our point of view, quite logical, because it corresponds to the established worldview of modern Russian citizens, their value-normative structure, as well as international legal and political standards and evolving processes of unification of the rights and political standardization of the systems of public-authoritative relations in the state. This socalled "synthetic model" of neo-conservative style of political thinking tries to combine the modern processes of modernization and sustainable socio-cultural values of the society. For example, modern sociological studies indicate the dominance in the Russian society of liberal individualist (38\%) and authoritarian communitarian (37\%) political views, as well as about $18 \%$ of mixed political ideas - combining both first and second political views (E.B. Shestopal, 2011).

Over the past ten years in the development of modernist neoconservative project there was no conceptual-ideal and ideological unity. At least in the official ideological concept of optimization of authoritative-law relations in Russia there were three different programs: the formation of a "strong state" that ensures social justice, stability, etc.; model of "sovereign democracy", which was more focused on the independence of the Russian state policy in the international arena, and its impact on the global political, economic, socio-cultural and other processes; project "social conservatism."

Thus, in 2000, the working President of the Russian Federation V.V. Putin declared that the main goal would be the building of the strong state, based on national and cultural traditions and different innovations which are typical for modernity that can strengthen the state and its independence. This neo-conservative project was supported by leading political actors. This version of conservative ideology was based on evolutionary development and gradual reform of the system of domestic state-legal organization.

These conservative projects were not isolated from each other; on the contrary, in the official rhetoric their evolutionary continuity was justified. For example, in official texts and statements their logical coherence were emphasizing, as well as synthetic approach (combination of traditional and modernizing ideas and values) to the state and legal development of the modern Russia was substantiated. This variant of conservatism defends only constant values and sustainable national ideas and does not accept that threatens those values and ideas, or does not attempt to provide them with adequate replacement in modernity (O. Kononova and Z. Yakimova 2013). And here the protective conservatism appears more often not in the form of sophisticated philosophical concept or coherent political ideology, but rather in the form of the orientation of the authorities, as some "political technology of authority, outreach program, simplified interpretative scheme, etc.

\subsection{Postmodern conservative ideological platform}

Postmodern conservative ideological platform is a certain kind of social technology, i.e. acts not as a conceptual and 
ideological paradigm of the organization and development of modern authoritative relations, but has the character of "technological option» (L. Kirsanova, O. Korotina, 2014) of national development strategy, which is constructed by the "elements of the old and new ideological systems that are prevalent in Russian society." It's a kind of fragmentary and skillfully "stitched" model of public-authoritative organization, legitimating itself as through traditional value-normative system of coordinates, and through today's dominant ideas in society, values and needs. These "fragmentation" and "contextuality" allow it to easily adapt to different philosophical systems of modern Russian society, as well as to "link" with the ever-changing international and domestic political context, geo-juridical trends unfolding in the Eurasian territory.

Postmodern style of conservative thought - this is a mosaic and contextual approach to the organization of authoritative relations. This postmodern approach was justly characterized by T.P. Vyazovik as a constructor, i.e. it is constructed from different ideological programs, blocks containing different value system (T.P. Vyazovik, 2011, p. 87). As the most famous postmodern conservative project a political brand "Project Russia", developed by a team of modern conservative oriented authors and having anonymous character (Project Russia, 2010) can be distinguished. It represents a constructed ideological system of socio-political, spiritual and moral foundations and geopolitical transformations and based on both the traditional values of Christian conservatism, and the new modernist principles of political practices.

The general logic of reasoning in various books, published with sufficiently large circulations, is associated with the formation of the ideational social system and ideocratic organization of authoritative relations. Ideational character (the term P.A. Sorokin) of political organization of relations based on the ideocratic type of moral worldview, in which the vertical value-normative hierarchy is oriented from the earthly world, the world of everyday life to the supersensible. In this ideational thinking is based on ideational ethics, which is characterized by disdain for the mundane (social) values, wealth, power, riches, bodily pleasures and so on. In this aspect of arguments about the organization of authoritative relations and the form of government the forming of some universal Christian conservative theocracy is supposed, where the supreme power and some public authorities are subject to the church and the spiritual and moral standards.

In addition, the authors of this project in a new way revived the idea of social class organization of society, arguing that exactly spiritually, morally and ideologically oriented "elite is able to die for its beliefs. The masses - are not. Their limits are instincts." Therefore, the scope of ideas is not the prerogative of the majority but the possessions of minority. And in this project one negatively evaluates the principle of social and political service, which, according to the authors, is often expressed in the mass in forms of instincts of justice, no meaningful and of no ideological and conceptual base, empty and useless in social and political life. However, this principle can be used to achieve the desired universal conservative Christian organization, i.e. the majority should serve ideological minority, realizing the "public instincts".

\subsection{Another project of the conservative transformation of the political and legal environment}

Another project of the conservative transformation of the political and legal environment is a "conservative revolution" (M. Remizov, 2002). To be fair it should be noted that it can be attributed to a real political transformation project of publicauthoritative organization in Russia de bene esse, because it is the intelligent response to the processes of liberaldemocratic modernization of the Russian political system, "The worldview in the spirit of "conservative revolution" is aimed not against metaphysical "enemies" but against the liberal credo, which lack political subjectivity and mobilization pathos"(B. Mezhuev, 2003).

\section{Concluding Remarks}

In modern Russian political reality three interrelated and co-determinant trends are manifested: first, the desire for spiritual and moral justification of public authorities, social and moral (ideocratical) responsibility of authoritativeadministrative elite; second, the requirement to integrate Western advances in human rights and freedoms, some democratic values with socio-cultural model of political organization and traditional (historically developed) practices of public-authoritative interaction; third, the need (at the level of mass political thinking) in the restoration of a strong state. And the concrete historical manifestation of state power has a moral and legal justification way of substitution in which the vertical of value-normative hierarchy is built on spiritual, absolute truths and dominants to socio-political ones.

The Russian public system two directions of transformation of forms and principles of the political process and optimization of the system of state authority are dominated: the modernizational and conservative. Modenizational project has obvious social and cultural components, based on a certain pattern of political transformation which is formed under specific historical conditions and continuity develops specific (universalist) style of political thinking and political organization. 
Conservative ideological and political platform is positioned as an alternative strategy for the transformation of public-authoritative organization based on the integration of traditional values, symbols, beliefs, etc. with the inevitable process of evolution of socio-political organization, in which concrete and holistic socio-cultural systems, providing political unity, public integrity, socio-cultural and ethno-political identity, etc. are dominated. In the Russian state fiveconservative ideological platforms are dominated: traditionalistic, "updates" Eurasian (neo-eurasian), modernistic conservative and postmodernistic ideologies, as well as a project of the conservative revolution (radical transformation).

\section{References}

Vyazovik, T.P. 2011. Attempts to Conservative Ideological Synthesis in the post-Soviet Territory // Ideological and Symbolic Space of post-Soviet Russia: dynamics, institutional environment, actors / ed. by O.J. Malinova. Moscow.

Guenon, R. 2002. The Symbols of the Sacred Science. Moscow.

Gorshkov, M.K. 2005 Citizens of New Russia: On the Stability and Variability of Public Mentality: abstracts at the seminar of the RAS. Moscow.

Dugin, A.G. 2004. The Project "Eurasia". Moscow.

Ilyin, I.A. 2003. The Way of Spiritual Renewal. Moscow.

Mannheim, K. 1994. The Diagnosis of our Time. Moscow: Yurist.

Mezhuev, B. 2003. American Fundamentalism and Russian "Conservative Revolution" // Logos. №1 (36).

Mikhalkov, N.S. 2010. The Right and the Truth. Manifesto of Enlightened Conservatism // Moscow: Russian Cultural Foundation, PH "Sibirsky tsiryulnik".

Nikitaev, B. 2005. An Agenda for Russia: power, politics, democracy // Logos. Number 5 (50).

Ovchinnikov, A.I., Mamychev A.Y., Manastyrny A.V. and Tyurin M.E., 2009. Juridical Archetypes in the Legal Policy of Russia. Rostovon-Don.

Okara, A.N. 2010. Conservatism as a Modernistic Project and as a Political Strategy of the Elite // Conservatism / Traditionalism: theory, forms of implementation and prospects. Science Seminar Materials. Vol. №3. Moscow.

Project Russia, 2011. The Fourth Book. The Big Idea. Moscow.

Remizov, M. 2002. The Experience of Conservative Criticism. Moscow.

Repnikov, A.V. 2007. Conservative Concept of Russia Rearrangement. Moscow.

Tikhomirov, L.A. 1992. The monarchical Statehood. St. Petersburg.

Shestopal, E.B. 2011. The Political Agenda of the Russian Government and Its Perception by Citizens // Political Studies. N 2.

Armagan, S. and Portugal Ferreira M. 2005. The Impact of Political Culture on Firms' Choice of Exploitation-Exploratio Internalization Strategy // International Journal of Cross Cultural Management. - London, SAGE. Vol 5 (3).

Buchanan, J. and Tullok G. 1962. The Calculus of Consent. Ann Arbor: Univ. of Michigan Press.

Clemens, E.S. and Cook J.M. 1999. Politics and Institutionalism: Explaining durability and change // Annual review of sociology. Palo Alto, Calif. Vol. 25.

Hoppe, R. 2002. Cultures of Public Policy Problems // Journal of Comparative Policy Analysis: Research and Practice. - London: Taylor \& Francis. No. 4

Eisenstadt, S.N. 1973. Tradition, Change, and modernity. N.Y., Sydney, Toronto.

Frohock, F. 1978 The Structure of politics // The American Political Science Review. Vol. 76. № 3.

Quermonne, J.-L. 1986. Les Regimes Politigues Occidentaux. P.

Kononova, O. and Yakimova Z. 2013. Competence as an Object for Assessmen and Measuremen in Training Quality Control System//World Applied Sciences journale. T.27. pp. 536-540.

Kirsanova, L. and Korotina O. 2014 On the Contents of the Protest Conscience in Russia. World.

March, J.G. and Olsen J.P. 1984. The New Institutionalism: Organizational Factors in Political Life // American political science review. Wash., D.C. Vol. 78. No 3.

Muouffe, Ch. 2000. The Democratic Paradox. London: Verso. 